\title{
Analysis of PIK3CA and Akt/protein kinase B in head and neck squamous cell carcinoma
}

\author{
IRINA FENIC $^{1}$, KLAUS STEGER ${ }^{1}$, CHRISTIN GRUBER $^{2}$, CHRISTOPH ARENS $^{3}$ and JOACHIM WOENCKHAUS ${ }^{4}$ \\ Departments of ${ }^{1}$ Urology and Pediatric Urology, ${ }^{2}$ Forensic Medicine, ${ }^{3} \mathrm{Head}$ \\ and Neck Surgery, and ${ }^{4}$ Pathology, University of Giessen, Germany
}

Received February 11, 2007; Accepted March 20, 2007

\begin{abstract}
PIK3CA, which encodes the catalytic subunit, p110alpha, of phosphatidylinositol 3-kinase (PI3K), is implicated in the development and progression of numerous neoplasias including head and neck squamous cell carcinoma (HNSCC). In the present study, we investigated the occurrence of PIK3CA hot-spot mutations in exons 9 and 20, the genomic gain and amplification of PIK3CA, the expression of PIK3CA mRNA and the $\mathrm{p} 110 \alpha$ protein, as well as the expression of phosphorylated-Akt (pAkt) in 33 cases of HNSCC and compared the results with the clinicopathological data. No non-synonymous mutations were detected. PIK3CA copy number gain and amplification were found in 36.4 and $9 \%$ of the cases, respectively, whereas mRNA overexpression was observed in $48.5 \%$ of the cases. No correlations could be stated between DNA gain, DNA amplification and mRNA expression, either between DNA or mRNA status and $\mathrm{p} 110 \alpha$ expression. Direct associations were found between PIK3CA gain and lymph node metastases $(\mathrm{p}=0.025)$ and between mRNA expression and tumour stage $(\mathrm{p}=0.015)$. A strong correlation was detected between $\mathrm{p} 110 \alpha$ and pAkt expression $(\mathrm{p}<0.001)$. Concluding, PIK3CA could be an oncogene implicated in HNSCC development. However, our data suggest that amplifications or mutations of this gene seldom occur in HNSCC and that epigenetic events can play an important role in advanced tumour stages.
\end{abstract}

\section{Introduction}

Head and neck squamous cell carcinoma (HNSCC) is the most frequent malignancy affecting the oral cavity, salivary glands, the larynx, and pharynx and has been associated with smoking and alcohol consumption (1). Despite advances in diagnosis and therapy, HNSCC still bears poor long-term survival rates (2). Considering the frequent genetic aberrations

Correspondence to: Dr Joachim Woenckhaus, Institute of Pathology, University of Giessen and Marburg, Langhans Str. 10, 35392 Giessen, Germany

E-mail:woenckh@yahoo.com

Key words: PIK3CA, mutation, real-time PCR, Western blotting, Akt which characterise HNSCC (3-5), it is of great interest to detect new molecular markers identifying patients with aggressive tumours and, hence, poor prognosis. Genetic alteration involving $3 \mathrm{q} 26$-ter is one of the most frequent events in HNSCC and has been related to disease progression and survival (6-9). PIK3CA (Acc. No. NM_006218), located at 3q26.3, encodes the catalytic subunit of phosphatidylinositol 3-kinase alpha (p110 $\alpha)$ and is one of the candidate oncogenes situated in this genomic region $(7,10)$.

Phosphatidylinositol 3-kinase alpha (PI3K) triggers the activation of the downstream target serine-threonine kinase AKT by inducing the phosphorylation of the Thr-308 and Ser-473 sites (pAKT) $(11,12)$. The PI3K-AKT pathway is implicated in many cellular functions associated with malignant behaviour, such as cell cycle progression, survival and invasion (reviewed in ref. 13). Recently, somatic missense mutations of the PIK3CA gene have been reported in carcinomas of the colon, breast, brain, liver, stomach, lung and ovary (reviewed in ref. 14). Most frequently they occur in the kinase (exon 20) and helical (exon 9) domains of the gene and bear oncogenic capacity in vitro and in vivo, as demonstrated by overexpression and deletion experiments in cell cultures (15-17) or tumour xenografts (18). The mutated p1 $10 \alpha$ protein is able to activate Akt in the absence of growth factors $(15,16,18)$. In ovarian carcinomas the occurrence of PIK3CA amplifications was inversely associated with the presence of the gene's mutations (19). Recent studies have reported on the somatic mutations of PIK3CA in HNSCC, although the incidence is lower than in other malignancies (20-22). HNSCC-derived cell lines showed more frequent somatic mutations than primary carcinomas (22).

In order to gain a comprehensive view about PIK3CA regulation in HNSCC, in the present study, we investigated the occurrence of PIK3CA hot-spot mutations in exons 9 and 20, the genomic gain and amplification of PIK3CA, the expression of PIK3CA mRNA and the p $110 \alpha$ protein, as well as the expression of phosphorylated-Akt (pAkt) in 33 cases of HNSCC and compared the results with the clinicopathological data.

\section{Material and methods}

Patients and tumour samples. The tissue and patient data were used in accordance with the declaration of Helsinki and the International Conference of Harmonisation - Good 
Clinical Practice. The anonymity of the patients investigated was preserved according to the data protection rules of the Human Medical Faculty, Giessen and the German state of Hessen.

Primary HNSCCs were selected from the fresh-frozen tumour archive of the Institute of Pathology, Giessen, Germany. The histological diagnosis was re-evaluated on H\&E-stained sections. Only samples encompassing $>70 \%$ tumour volume were considered for further investigations. Altogether, 33 cases were selected including 25 males and 8 females, 36 to 90 years of age (mean value 66) with the following tumour localizations: Twelve in the oral cavity, 16 in the larynx and 5 in the pharynx. The prognosis-associated factors assessed included primary tumour extent ( $\mathrm{t}$ ), histological differentiation (23), and the presence of lymph nodes metastases.

DNA, RNA and protein extraction. Fresh-frozen tissues were minced with a cryotom (thickness of the sections was $5 \mu \mathrm{m}$ ). The first and last sections were routinely stained with H\&E and used to sort the appropriate cases ( $>70 \%$ tumour volume). In each case, the minced tissue was split in two parts. DNA extraction was carried out with the QIAamp DNA Mini Kit (Qiagen, Germany) according to the manufacturer's instructions. RNA and protein extractions were performed using TRIzolR reagent, as recommended by the manufacturer (Life Technologies, Germany).

Mutation analysis. Exons 9 and 20 of PIK3CA were amplified from genomic DNA with primers complementary to the surrounding intronic sequences (14): Exon 9, forward 5'-TGAAAATGTATTTGCTTTTTCTGT-3' and reverse 5'TGTA AATTCTGCTTTATTTATTCC-3'; Exon 20, forward 5'-CATTTGCTCCAAACTGACCA-3' and reverse 5'GGTCTTTG CCTGCTGAGAGT-3'. Exon 9 was amplified using the HotStarTaq DNA Polymerase (Qiagen): $95^{\circ} \mathrm{C} 15 \mathrm{~min}$, $35 \mathrm{x}\left(95^{\circ} \mathrm{C} 30 \mathrm{sec}, 55^{\circ} \mathrm{C} 30 \mathrm{sec}, 72^{\circ} \mathrm{C} 45 \mathrm{sec}\right), 72^{\circ} \mathrm{C} 5 \mathrm{~min}$. Exon 20 was amplified using Taq DNA Polymerase (Qiagen): $95^{\circ} \mathrm{C} 2 \mathrm{~min}, 35 \mathrm{x}\left(95^{\circ} \mathrm{C} 30 \mathrm{sec}, 58^{\circ} \mathrm{C} 30 \mathrm{sec}, 72^{\circ} \mathrm{C} 45 \mathrm{sec}\right)$, $72^{\circ} \mathrm{C} 5 \mathrm{~min}$. As there is a known pseudogene on chromosome 22 sharing an almost exact match with PIK3CA exons 9-13 (14), the primers for exon 9 were placed over the few differences that exist for this exon (14). In addition, we checked the specificity of exon 9 amplification by employing the endonuclease, FspI, according to the manufacturer's protocol (New England Biolabs, Germany), which recognizes the sequence TGCGCA on the pseudogene but not the sequence TGAGCA on PIK3CA (nucleotides 1789-1794, Acc. No. NM_006218). If the pseudogene is co-amplified, then the endonuclease digestion produces two fragments which can be visualized using conventional agarose gel electrophoresis.

The PCR products were washed using the QIAquick PCR-purification Kit (Qiagen) and sequenced with the BigDye terminator method (Applied Biosystems; Warrington, United Kingdom or Forster City, CA, USA) on an autosequencer (ABI PRISM 3100) using the primers described above for exon 20, whereas nested primers were designed for exon 9: Forward 5'-AATATGACAAAGAAAGCTATA TAAGA-3', reverse 5'-GAAAAAGAAACAGAGAATCTC CAT-3'. In order to verify the sensitivity of the sequencing method used, we amplified genomic DNA with primers situated in exon 9, which are not able to discriminate between PIK3CA and its pseudogene (forward 5'-AATATGACAAA GAAAGCTATATAAGA-3', reverse 5'-GAAAAAGA AACAGAGAATCTCCAT-3'). The obtained PCR product (containing both PIK3CA and pseudogene fragments) was sequenced as described using two new nested primers (forward 5'-AATATGACAAAGAAAGCTATATAAGA-3', reverse 5'-GAAAAAGAAACAGAGAATCTCCAT-3'). Furthermore, a mixture containing equal quantities of this PCR product and an arbitrary PIK3CA-only PCR product (amount of pseudogene to PIK3CA 1:3), was sequenced.

Evaluation of PIK3CA gene status. The PIK3CA copy number was evaluated by qPCR (i-Cycler; BioRad, Germany) using $\mathrm{qPCR}^{\mathrm{TM}}$ mastermix for SYBR-Green (Eurogentec, Germany), primers to genomic intronic (between exon 19 and 20) sequences of PIK3CA (forward, 5'-CATTTGCTCCAAA CTGACCA-3'; reverse, 5'-AGAGATTGGCATGCTGT CGA-3') and the following protocol: $2 \mathrm{~min} 50^{\circ} \mathrm{C}, 6 \mathrm{~min}$ $95^{\circ} \mathrm{C}, 40 \mathrm{x}\left(20 \sec 95^{\circ} \mathrm{C}, 30 \sec 55^{\circ} \mathrm{C}, 30 \sec 72^{\circ} \mathrm{C}\right), 1 \mathrm{~min}$ $55^{\circ} \mathrm{C}, 20 \mathrm{~min} 55-95^{\circ} \mathrm{C}$ dissociation. Template DNA (80 ng) in a reaction volume of $25 \mu 1$ were employed in each case. Non-carcinomatous tissues (5 cases) were used to normalize the data. The differences between the cycle threshold value $(\mathrm{Ct}$, the cycle at which the fluorescence rises appreciably above the background fluorescence) of each carcinoma and the mean cycle threshold value of the non-carcinomatous tissue were designated as $\Delta \mathrm{Ct}$. The relative representation of the PIK3CA copy number (PIK3CA gain) in each HNSCC case with respect to non-tumour tissue is given by the formula $2^{-\Delta \mathrm{Ct}}$, which is a simplified calculation tool derived from the $\Delta \Delta \mathrm{Ct}$ method for gene expression analysis (24). In addition, the amount of PIK3CA-specific template was estimated in each carcinoma with respect to the control gene, TRAT1, situated on chromosome 3q13 (intronic primers: Forward, 5'-CATGTCAGGTAAGTGGCATT-3'; reverse, 5'GGGTCTTCTCGTTAGGACTTAG-3'). Non-carcinomatous tissues ( 5 cases) were used to normalize the data using the $\Delta \Delta \mathrm{Ct}$ method. The variation of the PIK3CA copy number with respect to TRAT1 was specified as 'amplification'. All experiments were performed in triplicate and the mean value was calculated for each case. PIK3CA copy number gain or amplification $\geq 2$ were considered significant.

Evaluation of PIK3CA mRNA status. Reverse transcription of total RNA was performed in each case using the OmniScript Kit (Qiagen). The obtained cDNA was evaluated by qPCR (i-Cycler; BioRad) using $\mathrm{qPCR}^{\mathrm{TM}}$ mastermix for SYBRGreen (Eurogentec), primers to cDNA sequences of PIK3CA (forward, 5'-CCAAGAATGCACAAAGACAAG-3'; reverse, 5'-AGAGATTGGCATGCTGTCGA-3') and PBGD as the housekeeping gene (forward, 5'- CCCACGCGAATCACT CTCAT-3'; reverse, 5'-TGTCTGGTAACGGCAATGCG-3'). The PCR conditions were: $2 \min 50^{\circ} \mathrm{C}, 6 \min 95^{\circ} \mathrm{C}, 40 \mathrm{x}$ $\left(20 \sec 95^{\circ} \mathrm{C}, 30 \sec 58^{\circ} \mathrm{C}, 30 \sec 72^{\circ} \mathrm{C}\right), 1 \min 58^{\circ} \mathrm{C}, 20 \min$ $58-95^{\circ} \mathrm{C}$ dissociation. The dissociation curve analysis checked the specificity of the products. All reactions were run in triplicate and the mean value was calculated for each case. Non-carcinomatous tissues ( 5 cases/run) were used to 


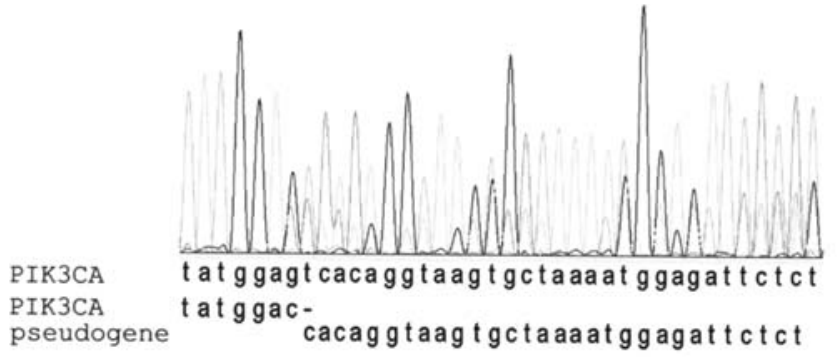

Figure 1. Fragment of exon 9 of PIK3CA. The differences between PIK3CA and its known pseudogene on chromosome 22 were successfully detected with the sequencing method used.

normalize the data using the $\Delta \Delta \mathrm{Ct}$ method (24). Values $\geq 2$ reflect an overexpression of PIK3CA mRNA.

Western blot analyses. Four samples containing $5 \mu 1$ of each protein extract were resolved by SDS-PAGE on four identical gradient acrylamide gels (4-12\%) (Invitrogen, Germany) under reducing conditions and, subsequently, electroblotted onto four nitrocellulose transfer membranes (Invitrogen). In order to control the blotting performance, the gels were stained with Coomassie-Brilliant-Blue. Immunodetection was performed separately at room temperature overnight with anti-p $110 \alpha$ (Abcam, Germany; rabbit polyclonal, 1:200), anti-beta actin (Abcam; rabbit polyclonal; loading control; 1:500), anti-Akt (Cell Signaling, Germany; rabbit polyclonal, 1:1000), and anti-pAkt (Cell Signaling; rabbit polyclonal, 1:2000). The reaction was visualized with the APAAP mouse detection system (DAKO, Germany) using mouse-anti-rabbit and rabbit-anti-mouse secondary antibodies (DAKO) and NBT-BCIP (KPL, USA) as the phosphatase substrate. Negative controls were performed omitting the primary antibodies. All experiments were performed in duplicate. The color intensity of the bands was computationally assessed with the TotalLab program TL100 (limited license, www.nonlinear.com). For each experiment and antibody, a sensitivity test was run using protein extracts diluted 1, 1:2, 1:4 and 1:8 and the band intensities were compared. The band intensity that corresponds to anti-p110 $\alpha$ was calculated as the fold change to that of anti-beta actin in each case. Similarly, the band intensity that corresponds to anti-pAkt was calculated as the fold change to that of anti-Akt in each case. Reliable data (presence of the reference protein) was obtained in 29 cases for $\mathrm{p} 110 \alpha$ and in 27 cases for pAkt.

Statistical analysis. The associations between PIK3CA genetic abnormalities, RNA status, p110 $\alpha_{-}$, pAkt-protein expression to each other and to the clinicopathological parameters were assessed by the Spearman rank correlation coefficient. In addition, PIK3CA gain, amplification and mRNA expression values were dichotomized (values $<2$ vs $>2$ ) and compared to the clinicopathological data using Fisher's exact test. For this purpose, patient age $(<66$ vs $>66)$ and tumour stage $(\mathrm{T} 1+\mathrm{T} 2$ vs T3 + T4) were also dichotomized. Associations with the tumour location (oral cavity, larynx, pharynx) were estimated with Chi-square tests. All analyses were performed using the SPSS software for Windows ${ }^{\mathrm{TM}}$, release 11.0. A probability of error $<5 \%$ was regarded as significant.

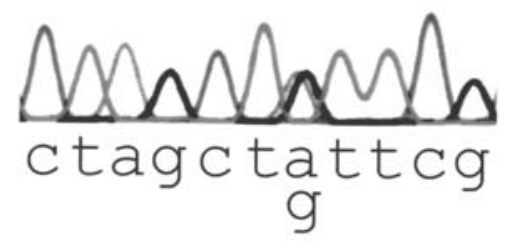

Figure 2. Fragment of exon 20 of PIK3CA. A point-mutation (A3128G) leads to the replacement of codon 'cta' with 'ctg', both of them encoding the aminoacid leucin.

\section{Results}

Mutation analysis. Under the used PCR conditions, the primers for exon 9 specifically recognized the PIK3CA sequence and did not amplify the known PIK3CA pseudogene, as verified by the FspI endonuclease-digestion method (data not shown). This was also confirmed by the sequencing chromatograms, where none of the known differences between PIK3CA and its pseudogene could be observed in the cases investigated (data not shown). However, applying the same sequencing method to the PCR products containing fragments of PIK3CA and its pseudogene (1:1 and 1:3), the nucleotide profile corresponding to the pseudogene was clearly recognized on the cromatograms (Fig. 1), demonstrating the sensitivity of the employed method. Only one synonymous point mutation (A3128G) leading to the replacement of the codon 'cta' with 'ctg' (both encoding leucin) could be found in exon 20 in one HNSCC case (Fig. 2). No non-synonymous mutations were detected in exons 9 and 20.

PIK3CA gain, amplification and mRNA expression. The relationship between PIK3CA copy number gain, PIK3CA amplification and mRNA expression was assessed in 33 HNSCCs using quantitative PCR methods and 5 samples of non-tumoural tissue to normalise the data. The cycle threshold values obtained for the non-tumoural cases in each qPCR were similar to each other and were around 30. The PIK3CA copy number in the carcinomas compared to the nontumoural tissue ranged between 0.22 and 7.89 (mean 2.27). Twelve out of $33(36.4 \%)$ HNSCCs showed PIK3CA gains $>2$ and 4 cases (12.1\%) showed gains $>4$ (high level). The PIK3CA amplification related to TRAT1 in the carcinomas compared to the non-tumoural tissue ranged between 0.4 and 7.46 (mean 1.18). Only 3 HNSCC (9\%) displayed amplifications $>2$ and 1 of these cases harboured a high level amplification $(>4)$. The mRNA expression ranged between 0.38 and 90.5 (mean 8.28) and 16 out of $33(48.5 \%$ ) cases showed an overexpression $(>2)$. These results in connection with the clinicopathological data are summarised in Table I. A closer analysis of the HNSCCs displaying PIK3CA amplification (3 cases) showed that only 1 of them also harboured a DNA copy number gain (amplification $=7.46$, gain $=7.89$ ). In this case, elevated mRNA and protein expressions could be stated. Comparing the DNA status (gain or amplification) with the mRNA expression revealed that in 7 HNSCCs $(21 \%)$ elevated copy number gains were associated with mRNA overexpression whereas 8 cases $(24 \%)$ displayed an enhanced mRNA expression and no significant DNA overrepresen- 
Table I. PIK3CA-related parameters and pAkt expression in connection with clinical characteristics in 33 HNSCC cases.

\begin{tabular}{|c|c|c|c|c|c|c|c|c|c|c|}
\hline No. & Age & $\begin{array}{l}\text { Tumour } \\
\text { location }^{\mathrm{a}}\end{array}$ & $\begin{array}{c}\mathrm{T}- \\
\text { stage }\end{array}$ & $\begin{array}{l}\text { Lymph } \\
\text { node } \\
\text { metastases }\end{array}$ & $\begin{array}{l}\text { Tumour } \\
\text { grading }\end{array}$ & $\begin{array}{l}\text { PIK3CA } \\
\text { gain }\end{array}$ & $\begin{array}{l}\text { PIK3CA } \\
\text { amplifi- } \\
\text { cation }\end{array}$ & $\begin{array}{c}\text { PIK3CA } \\
\text { mRNA } \\
\text { expression }\end{array}$ & $\begin{array}{c}\text { p110 } \alpha \\
\text { expression }\end{array}$ & $\begin{array}{c}\text { pAkt } \\
\text { expression }\end{array}$ \\
\hline 1 & 80 & 1 & 2 & Yes & 2 & 1.47 & 0.61 & 1.80 & 0.01 & 1.00 \\
\hline 2 & 62 & 3 & 1 & No & 2 & 2.65 & 0.61 & 90.50 & 0.33 & 1.00 \\
\hline 3 & 56 & 1 & 2 & No & 2 & 1.67 & 1.15 & 0.96 & 0.61 & 1.80 \\
\hline 4 & 68 & 3 & 4 & Yes & 2 & 2.18 & 0.87 & 6.49 & 0.01 & 0.20 \\
\hline 5 & 62 & 3 & 3 & Yes & 3 & 1.70 & 2.83 & 2.92 & 0.33 & 4.65 \\
\hline 6 & 70 & 2 & 1 & No & 3 & 0.22 & 1.23 & 1.62 & 0.01 & 0.49 \\
\hline 7 & 84 & 2 & 2 & No & 2 & 0.32 & 1.23 & 0.84 & 0.30 & 11.67 \\
\hline 8 & 90 & 2 & 3 & Yes & 2 & 1.84 & 1.15 & 2.73 & 0.23 & 3.47 \\
\hline 9 & 63 & 2 & 4 & No & 2 & 1.15 & 1.00 & 4.43 & 0.31 & 5.13 \\
\hline 10 & 67 & 2 & 3 & No & 2 & 1.97 & 1.00 & 3.36 & 0.01 & 0.12 \\
\hline 11 & 85 & 1 & 1 & No & 2 & 0.82 & 0.93 & 6.54 & 2.46 & 6.00 \\
\hline 12 & 65 & 2 & 2 & No & 2 & 1.67 & 0.57 & 1.62 & 1.10 & 3.59 \\
\hline 13 & 61 & 3 & 4 & Yes & 2 & 2.20 & 0.61 & 40.70 & 0.78 & 2.890 \\
\hline 14 & 85 & 2 & 4 & Yes & 2 & 3.10 & 1.00 & 0.61 & 0.01 & 0.10 \\
\hline 15 & 75 & 1 & 1 & No & 2 & 1.79 & 0.43 & 0.81 & 6.00 & 5.59 \\
\hline 16 & 48 & 1 & 1 & No & 2 & 5.17 & 1.00 & 0.69 & 5.16 & 8.99 \\
\hline 17 & 78 & 2 & 3 & Yes & 2 & 2.11 & 0.81 & 12.50 & 0.41 & 1.62 \\
\hline 18 & 36 & 1 & 3 & Yes & 3 & 3.50 & 0.61 & 4.20 & 0.46 & 0.99 \\
\hline 19 & 76 & 2 & 4 & Yes & 3 & 1.46 & 0.57 & 8.00 & 2.33 & 8.40 \\
\hline 20 & 68 & 1 & 2 & No & 2 & 0.85 & 0.93 & 4.65 & 0.38 & 2.64 \\
\hline 21 & 70 & 2 & 4 & Yes & 2 & 7.89 & 7.46 & 32.00 & 0.22 & 0.40 \\
\hline 22 & 70 & 2 & 4 & Yes & 3 & 0.64 & 1.15 & 23.70 & 0.33 & 1.00 \\
\hline 23 & 62 & 2 & 4 & No & 2 & 1.24 & 0.46 & 1.96 & 1.22 & 13.89 \\
\hline 24 & 59 & 1 & 2 & No & 3 & 1.49 & 0.93 & 10.70 & 0.61 & 4.15 \\
\hline 25 & 58 & 2 & 4 & Yes & 3 & 2.79 & 1.15 & 2.00 & 0.44 & 4.20 \\
\hline 26 & 70 & 2 & 3 & No & 3 & 1.13 & 1.00 & 0.68 & 0.85 & 5.79 \\
\hline 27 & 67 & 3 & 3 & No & 3 & 0.95 & 2.00 & 1.68 & 0.80 & 5.55 \\
\hline 28 & 64 & 2 & 2 & Yes & 2 & 4.92 & 0.40 & 0.38 & 0.01 & nd \\
\hline 29 & 60 & 2 & 3 & No & 2 & 7.46 & 0.93 & 1.25 & 0.01 & nd \\
\hline 30 & 70 & 1 & 2 & Yes & 2 & 3.60 & 1.15 & 1.00 & nd & nd \\
\hline 31 & 48 & 1 & 1 & Yes & 2 & 1.45 & 0.70 & 0.50 & nd & nd \\
\hline 32 & 55 & 1 & 1 & No & 3 & 1.80 & 1.32 & 0.66 & nd & nd \\
\hline 33 & 49 & 1 & 1 & Yes & 3 & 1.93 & 1.23 & 0.86 & nd & nd \\
\hline
\end{tabular}

HNSCC, head and neck squamous cell carcinoma. ${ }^{\mathrm{a}} 1$ = oral cavity, 2 = larynx, 3 = pharynx; nd, not determined.

tation. In one case, DNA amplification (but no gain) and mRNA overexpression coexisted. No significant associations could be stated between DNA gain, DNA amplification and mRNA expression, as assessed by the Spearman rank correlation coefficient or Fisher's exact test. Correlations were found between PIK3CA gain and lymph node metastasis ( $\mathrm{rs}=0.388, \mathrm{p}=0.025)$, RNA expression and T-classification ( $\mathrm{rs}=0.419, \mathrm{p}=0.015$ ) and between PIK3CA amplification and the histological tumour grading $(\mathrm{rs}=0.377, \mathrm{p}=0.031)$. The first two associations were confirmed by Fisher's exact test ( $\mathrm{p}=0.032, \mathrm{p}=0.037$, respectively) but the last could not be confirmed, due to the small number of cases which showed amplifications.

p110 $\alpha$ - and pAKT-protein expression. The sensitivity tests for the Western blot method used demonstrated a reliable detection capacity for each antibody under the employed conditions (data not shown). The $\mathrm{p} 110 \alpha$ protein expression compared to $\beta$-actin ranged between 0 and 6.01 (mean 0.88) (Fig. 3) and that of pAkt compared to unphosphorylated Akt ranged between 0.1 and 13.89 (mean 3.9) (Fig. 4). In the non-tumoural tissue ( 5 cases) the levels of p1 10 (mean 0.30 ) 
$\begin{array}{lllllllllllllllllllllllllllll}1 & 2 & 3 & 4 & 5 & 6 & 7 & 8 & 9 & 10 & 11 & 12 & 13 & 14 & 15 & 16 & 17 & 18 & 19 & 20 & 21 & 22 & 23 & 24 & 25 & 26 & 27 & 28 & 29\end{array}$

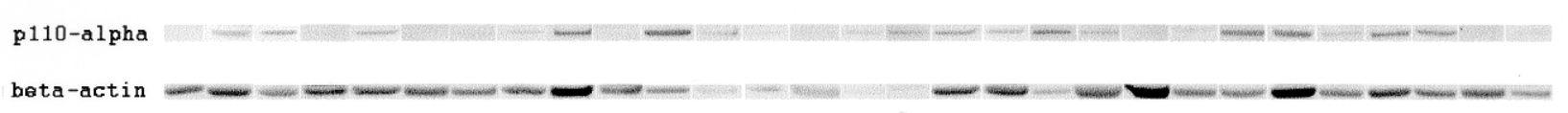

Figure 3. Western blot analysis of p110 $\alpha$ expression in 29 informative cases.

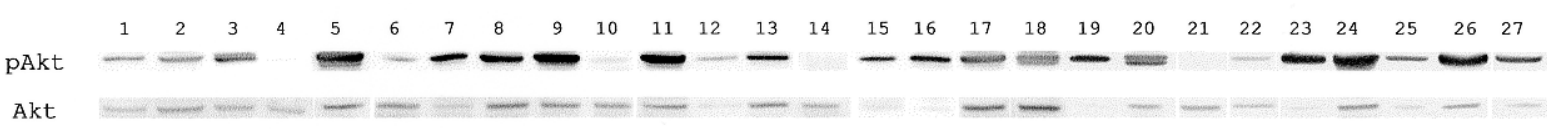

Figure 4. Western blot analysis of pAkt expression in 27 informative cases. The double band in cases 18 and 20 represent two isoforms of pAkt; the most intensive band was considered for calculation.

and pAkt (mean 3.48) were slightly lower than those detected in HNSCC (data not shown). The Spearman rank correlation coefficient demonstrated a strong correlation between $\mathrm{p} 110 \alpha$ and pAkt expression in the carcinomas ( $\mathrm{rs}=0.728, \mathrm{p}<0.001$ ). No significant association could be observed between p110 $\alpha$ or pAkt and PIK3CA gain, amplification or mRNA expression. No associations were found between protein expressions and clinicopathological data.

\section{Discussion}

The PI3K-AKT pathway plays a central role in many physiological processes and is implicated in malignant transformation by promoting cell cycle progression, survival and invasion (reviewed in ref. 13). Genomic aberrations of PIK3CA have been frequently found in HNSCC and encompass copy number gains and amplifications or oncogenic missense mutations $(21,22,25-27)$. In a previous study, using fluorescence in situ hybridisation (FISH) methods and a YAC probe covering about $1.7 \mathrm{Mb}$, we showed that copy number gains at 3q26.3, encompassing PIK3CA, represent an early event in HNSCC and are more consistent in advanced tumours (28). However, this approach does not exclude the possibility that other oncogenes situated near PIK3CA could be responsible for the malignant transformation in HNSCC. A good example is ECT2, which has been recently detected together with PIK3CA within an amplified cluster at 3q26.31-32 in oesophageal squamous cell carcinomas (25) and has been suggested to harbour oncogenic functions (29). Other genes clustered at $3 q 26.3$ are ZASC1 (3q26.33) and SCCRO (3q26.3), which have already been implicated in HNSCC carcinogenesis (26,30-32). In the present study, we employed PCR-based methods in order to specifically detect abnormalities which affect PIK3CA. Amplifications of the gene were detected in a limited number of cases (9\%), whereas copy number gains were common (36.4\%). Only one tumour displayed both amplification and gain. Therefore, the copy number gain of PIK3CA detected in our data set is possibly connected to the polyploidy of chromosome 3 , or its short arm $3 \mathrm{q}$, which are frequent events in HNSCC (3-5). In a previous study employing multiplex and quantitative real-time PCR, Pedrero et al reported that $37 \%$ of the HNSCC cases investigated, exhibited PIK3CA amplifications which were not related to the ploidy of chromosome 3 (27). The different incidences of amplification found by us and Pedrero et al could be explained by the reference genes used in the PCR approaches (TRAT1 situated at 3q13 and COL7A1 situated at 3p21, respectively). The short arm of chromosome 3 (3p) shows frequent genomic losses in HNSCC (3-5) and the monosomy of 3p was described as the only chromosomal alteration in diploid oral squamous cell carcinoma (33). Therefore, choosing the reference gene on $3 p$ could introduce bias in the evaluation of PIK3CA amplification. Another explanation could reside in the fact that Pedrero et al (27) investigated many pharynxlocated HNSCCs $(61 \%$ of all the cases), which, with the exception of the nasopharynx localisation, have been related to pronounced tumour aggressiveness (34), and also, they only included in their study patients with a history of tobacco and alcohol consumption. A recent report, published when the present manuscript was in preparation, describes a lower incidence of PIK3CA amplifications (16.7\%) in a mixed group of smoking and non-smoking patients with oral squamous cell carcinomas (22). The authors used a quantitative real-time PCR approach and COL7A1 as the reference gene. Neither in our study nor in the other 2 above mentioned publications $(22,27)$, could any correlation between PIK3CA amplification and tumour stage be stated. The lack of association with advanced tumoural stage (T-classification) and the high incidence of 3q26 and/or PIK3CA overrepresentation in premalignant lesion of the upper aerodigestive tract $(7,22,27,28)$ suggest that the genetic amplification of PIK3CA represents an early event in the development of HNSCC conferring growth- and spread-advantages to the tumoural cells, but this amplification is no longer specifically selected in advanced invasive carcinomas which harbour genetic defects, thus enabling more aggressive transformations. Missense mutations occurring in the helical (exon 9) or kinase domain (exon 20) of PIK3CA are oncogenic (14) and have been reported to be associated with advanced stages of HNSCC (22). However, the incidence of somatic point mutations in the hot-spot exons is reduced in $\operatorname{HNSCC}(21,22)$ compared to other malignancies (reviewed in ref. 14). In the present study, we could not find any non-synonymous point mutation in exons 9 and 20 of PIK3CA. The sensitivity of our sequencing method was proved by the faithful detection of the known differences between PIK3CA and its pseudogene (19).

In order to investigate the relationship between PIK3CA genomic status and its expression, we quantitatively assessed the transcription (reverse transcription followed by qPCR) and 
translation (Western blotting) of the gene. The functional implication of $\mathrm{p} 110 \alpha$ in HNSCC, reflected by the degree of activation (phosphorylation) of its downstream effector, Akt, was investigated by Western blot analysis. Almost half of the carcinomas displayed an enhanced mRNA expression and in some of them this could be related to genomic gains and/or amplifications. However, no significant association could be stated between genomic abnormalities and mRNA expression. In vitro studies have shown that the genomic gain of PIK3CA is followed by an increased transcription and translation in human ovarian and cervical cancer cell lines $(35,36)$, and similar data has also been reported in oral squamous carcinoma cell lines $(22,37)$. However, our results, in line with those obtained by Pedrero et al (27), suggest that epigenetic events also influence $\mathrm{p} 110 \alpha$ expression in HNSCC. mRNA expression was associated with an increased tumoural stage. These data support the hypothesis that epigenetic mechanisms regulate the transcription of PIK3CA in advanced tumour stages. One possibility is given by the inactivation of the tumour suppressor, p53, leading to enhanced PIK3CA transcription, as observed in HNSCC cell lines (37).

The strong correlation between $\mathrm{p} 110 \alpha$ and pAkt expressions detected by Western blotting confirms the importance of the protein kinase Akt as a downstream effector of p110 $\alpha$ in HNSCC. Given that PI3K is the main upstream regulator of Akt, our results indirectly demonstrate the activity of PI3K in HNSCC. The missing correlation of p1 $10 \alpha$ with the PIK3CA mRNA expression could be due to transcriptional or posttranscriptional mechanisms which finely tune the expression level of the catalytic subunit of PI3K. It is possible that p110 $\alpha$ is only transiently overexpressed in tumour cells that exhibit enhanced mRNA and, as a consequence, is difficult to detect in heterogeneous tissue. Although p110 $\alpha$ and pAkt were more weakly expressed overall in the non-tumoural tissues investigated than in the HNSCCs, there were also benign cases which strongly expressed one or both proteins (data not shown) so that the mean values of $\mathrm{p} 110 \alpha$ and pAkt in the nontumoral tissue were only slightly lower than in the carcinomas. These data are in line with previously reported observations (27) and suggest that p110 and its downstream effector, pAk, have similar basal expression levels in malignant and nonmalignant tissues of the upper aerodigestive tract. A transcriptional up-regulation, as observed by us in the HNSCC cases, could result in a minimal rise of the $110 \alpha$ protein expression level which is sufficient to confer growth advances to the malignant cells, but too low to be reliably detected by Western blotting.

Concluding, PIK3CA could be one of the oncogenes at $3 q 26.3$ implicated in the early stages of HNSCC development. Our data, however, suggest that the amplifications or mutations of this gene seldom occur in HNSCC and that epigenetic events can play an important role in advanced tumour stages.

\section{References}

1. Sturgis EM, Wie Q and Spitz MR: Descriptive epidemiology and risk factors for head and neck cancer. Semin Oncol 726733, 2004.

2. Hardisson D: Molecular pathogenesis of head and neck squamous cell carcinoma. Eur Arch Otorhinolaryngol 260: 502-508, 2003.
3. Gollin SM: Chromosomal alterations in squamous cell carcinomas of the head and neck: window to the biology of disease. Head Neck 23: 238-253, 2001.

4. Sparano A, Quesnelle KM, Kumar MS, Wang Y, Sylvester AJ, Feldman M, Sewell DA, Weinstein GS and Brose MS: Genomewide profiling of oral squamous cell carcinoma by array-based comparative genomic hybridization. Laryngoscope 116: 735-741, 2006.

5. Hermsen M, Alonso Guervos M, Meijer G, van Diest P, Suarez Nieto C, Marcos CA and Sampedro A: Chromosomal changes in relation to clinical outcome in larynx and pharynx squamous cell carcinoma. Cell Oncol 27: 191-198, 2005.

6. Liehr T, Ries J, Wolff E, Fiedler W, Dahse R, Ernst G, Steininger H, Koscielny S, Girod S and Gebhart E: Gain of DNA copy number on chromosomes 3q26-qter and 5p14-pter is a frequent finding in head and neck squamous cell carcinomas. Int J Mol Med 2: 173-179, 1998.

7. Redon R, Muller D, Caulee K, Wanherdrick K, Abecassis J and du Manoir S: A simple specific pattern of chromosomal aberrations at early stages of head and neck squamous cell carcinomas: PIK3CA but not p63 gene as a likely target of 3q26-qter gains. Cancer Res 61: 4122-4129, 2001.

8. Singh B, Stoffel A, Gogineni S, Poluri A, Pfister DG, Shaha AR, Pathak A, Bosl G, Cordon-Cardo C, Shah JP and Rao PH: Amplification of the $3 \mathrm{q} 26.3$ locus is associated with progression to invasive cancer and is a negative prognostic factor in head and neck squamous cell carcinomas. Am J Pathol 161: 365-371, 2002.

9. Hashimoto Y, Oga A, Kawauchi S, Furuya T, Shimizu N, Nakano T, Imate Y, Yamashita $\mathrm{H}$ and Sasaki K: Amplification of 3q26 approximately qter correlates with tumor progression in head and neck squamous cell carcinomas. Cancer Genet Cytogenet 129: 52-56, 2001.

10. Chen YJ, Lin SC, Kao T, Chang CS, Hong PS, Shieh TM and Chang KW: Genome-wide profiling of oral squamous cell carcinoma. J Pathol 204: 326-332, 2004.

11. Kettunen E, el-Rifai W, Bjorkqvist AM, Wolff H, Karjalainen A, Anttila S, Mattson K, Husgafvel-Pursiainen K and Knuutila S: A broad amplification pattern at $3 \mathrm{q}$ in squamous cell lung cancer - a fluorescence in situ hybridization study. Cancer Genet Cytogenet 117: 66-70, 2000.

12. Bockmuhl U, Schluns K, Kuchler I, Petersen S and Petersen I: Genetic imbalances with impact on survival in head and neck cancer patients. Am J Pathol 157: 369-375, 2000.

13. Osaki M, Oshimura M and Ito H: PI3K-Akt pathway: its functions and alterations in human cancer. Apoptosis 9: 667-676, 2004.

14. Karakas B, Bachman KE and Park BH: Mutation of the PIK3CA oncogene in human cancers. Br J Cancer 94: 455-459, 2006.

15. Ikenoue T, Kanai F, Hikiba Y, Obata T, Tanaka Y, Imamura J, Ohta M, Jazag A, Guleng B, Tateishi K, Asaoka Y, Matsumura M, Kawabe T and Omata M: Functional analysis of PIK3CA gene mutations in human colorectal cancer. Cancer Res 65: 4562-4567, 2005.

16. Kang S, Bader AG and Vogt PK: Phosphatidylinositol 3-kinase mutations identified in human cancer are oncogenic. Proc Natl Acad Sci USA 102: 802-807, 2005.

17. Samuels Y, Diaz LA Jr, Schmidt-Kittler O, Cummins JM, Delong L, Cheong I, Rago C, Huso DL, Lengauer C, Kinzler KW, Vogelstein B and Velculescu VE: Mutant PIK3CA promotes cell growth and invasion of human cancer cells. Cancer Cell 7: 561-573, 2005.

18. Bader AG, Kang S and Vogt PK: Cancer-specific mutations in PIK3CA are oncogenic in vivo. Proc Natl Acad Sci USA 103: 1475-1479, 2006.

19. Campbell IG, Russell SE, Choong DY, Montgomery KG, Ciavarella ML, Hooi CS, Cristiano BE, Pearson RB and Phillips WA: Mutation of the PIK3CA gene in ovarian and breast cancer. Cancer Res 64: 7678-7681, 2004

20. Or YY, Hui AB, To KF, Lam CN and Lo KW: PIK3CA mutations in nasopharyngeal carcinoma. Int J Cancer 118: 1065-1067, 2006.

21. Qiu W, Schonleben F, Li X, Ho DJ, Close LG, Manolidis S, Bennett BP and Su GH: PIK3CA mutations in head and neck squamous cell carcinoma. Clin Cancer Res 12: 1441-1446, 2006.

22. Kozaki K, Imoto I, Pimkhaokham A, Hasegawa S, Tsuda H, Omura $\mathrm{K}$ and Inazawa J: PIK3CA mutation is an oncogenic aberration at advanced stages of oral squamous cell carcinoma. Cancer Sci 97: 1351-1358, 2006. 
23. Union International contre le Cancer: TNM classification of malignant tumours. Sobin LH and Wittekind C (eds). 6th edition. Wiley-Liss, New York, 2002.

24. Pfaffl MW: A new mathematical model for relative quantification in real-time RT-PCR. Nucleic Acids Res 29: 2002-2007, 2001.

25. Yen CC, Chen YJ, Pan CC, Lu KH, Chen PC, Hsia JY, Chen JT, Wu YC, Hsu WH, Wang LS, Huang MH, Huang BS, Hu CP, Chen PM and Lin $\mathrm{CH}$ : Copy number changes of target genes in chromosome 3q25.3-qter of esophageal squamous cell carcinoma: TP63 is amplified in early carcinogenesis but downregulated as disease progressed. World J Gastroenterol 11: 1267-1272, 2005.

26. Lin SC, Liu CJ, Ko SY, Chang HC, Liu TY and Chang KW: Copy number amplification of 3q26-27 oncogenes in microdissected oral squamous cell carcinoma and oral brushed samples from areca chewers. J Pathol 206: 417-422, 2005.

27. Pedrero JM, Carracedo DG, Pinto CM, Zapatero AH, Rodrigo JP, Nieto CS and Gonzalez MV: Frequent genetic and biochemical alterations of the PI 3-K/AKT/PTEN pathway in head and neck squamous cell carcinoma. Int J Cancer 114: 242-248, 2005.

28. Woenckhaus J, Steger K, Werner E, Fenic I, Gamerdinger U, Dreyer T and Stahl U: Genomic gain of PIK3CA and increased expression of $\mathrm{p} 110 \mathrm{alph}$ are associated with progression of dysplasia into invasive squamous cell carcinoma. J Pathol 198: 335-342, 2002.

29. Saito S, Liu XF, Kamijo K, Raziuddin R, Tatsumoto T, Okamoto I, Chen X, Lee CC, Lorenzi MV, Ohara N and Miki T: Deregulation and mislocalization of the cytokinesis regulator ECT2 activate the Rho signaling pathways leading to malignant transformation. J Biol Chem 279: 7169-7179, 2004.

30. Estilo CL, O-Charoenrat P, Ngai I, Patel SG, Reddy PG, Dao S, Shaha AR, Kraus DH, Boyle JO, Wong RJ, Pfister DG, Huryn JM, Zlotolow IM, Shah JP and Singh B: The role of novel oncogenes squamous cell carcinoma-related oncogene and phosphatidylinositol 3-kinase p1 10alpha in squamous cell carcinoma of the oral tongue. Clin Cancer Res 9: 2300-2306, 2003.
31. Imoto I, Yuki Y, Sonoda I, Ito T, Shimada Y, Imamura M and Inazawa J: Identification of ZASC1 encoding a Kruppel-like zinc finger protein as a novel target for $3 \mathrm{q} 26$ amplification in esophageal squamous cell carcinomas. Cancer Res 63: 5691-5696, 2003.

32. Sarkaria I, O-Charoenrat P, Talbot SG, Reddy PG, Ngai I, Maghami E, Patel KN, Lee B, Yonekawa Y, Dudas M, Kaufman A, Ryan R, Ghossein R, Rao PH, Stoffel A, Ramanathan Y and Singh B: Squamous cell carcinoma related oncogene/DCUN1D1 is highly conserved and activated by amplification in squamous cell carcinomas. Cancer Res 66: 9437-9444, 2006

33. Hemmer J, Kraft K and Van Heerden WF: Correlation between DNA ploidy by flow cytometry and chromosome 3 aberration in oral squamous cell carcinoma. Oncol Rep 15: 243-246, 2006.

34. Baatenburg de Jong RJ, Hermans J, Molenaar J, Briaire JJ and le Cessie S: Prediction of survival in patients with head and neck cancer. Head Neck 23: 718-724, 2001.

35. Shayesteh L, Lu Y, Kuo WL, Baldocchi R, Godfrey T, Collins C, Pinkel D, Powell B, Mills GB and Gray JW: PIK3CA is implicated as an oncogene in ovarian cancer. Nat Genet 21: 99-102, 1999

36. Ma YY, Wei SJ, Lin YC, Lung JC, Chang TC, Whang-Peng J, Liu JM, Yang DM, Yang WK and Shen CY: PIK3CA as an oncogene in cervical cancer. Oncogene 19: 2739-2744, 2000.

37. Singh B, Reddy PG, Goberdhan A, Walsh C, Dao S, Ngai I, Chou TC, O-Charoenrat P, Levine AJ, Rao PH and Stoffel A: p53 regulates cell survival by inhibiting PIK3CA in squamous cell carcinomas. Genes Dev 16: 984-993, 2002. 